\title{
OBESIDADE INFANTIL: IMPORTÂNCIA DA ORIENTAÇÃO PREVENTIVA DO ENFERMEIRO
}

\section{ARTIGO ORIGINAL}

OLIVEIRA, Andréia Braga de ${ }^{1}$, TOMAZ, Priscilla Steffani Santos²

OLIVEIRA, Andréia Braga de. TOMAZ, Priscilla Steffani Santos. Obesidade infantil: importância da orientação preventiva do enfermeiro. Revista Científica Multidisciplinar Núcleo do Conhecimento. Ano 06, Ed. 03, Vol. 06, pp. 61-70. Março de 2021. ISSN: 2448-0959, Link de acesso: https://www.nucleodoconhecimento.com.br/saude/orientacao-preventiva, $\quad$ DOI: 10.32749/nucleodoconhecimento.com.br/saude/orientacao-preventiva

\section{RESUMO}

Obesidade é quando o nível de gordura ultrapassa os padrões considerados normais contidas no organismo, causado pelo consumo excessivo de calorias na alimentação que supera os valores usados pelo organismo para manutenção de suas funções orgânicas, tendo fatores agravantes como questões sociais, biológicas, culturais e políticas. $\mathrm{O}$ atual trabalho tem como proposta, descrever a importância da orientação preventiva do enfermeiro diante de um prognóstico ou diagnóstico confirmado em que crianças acima do peso possam desenvolver a obesidade infantil. Trata-se de estudo bibliográfico, descritivo de natureza exploratória, mediante artigos selecionados nas bases de dados do Núcleo do conhecimento (Multidisciplinary Scientific Journal), ABESO (Associação Brasileira para o Estudo da Obesidade e da Síndrome Metabólica) e Scielo (Scientifie Eletronic Library Online), nos meses de Fevereiro a Dezembro de 2017. Espera-se, com essa

\footnotetext{
${ }^{1}$ Pós-graduação em enfermagem dermatológica pela Kuality Brasil (2019). Pós-graduação em urgência e emergência pela Faveni(2019). Pós-graduação em home care pela Faveni(2020). Especialização em Bombeira civil- Instrutora GSR(2020). Graduação - Enfermeira pela Faculdade de Aracaju (FACAR - 2017). Técnico Técnico em enfermagem pelo Hospital são Lucas(2009).

${ }^{2}$ Orientadora. Especialização em Metodologia do Ensino da Matemática.
} 
pesquisa, descrever as ações de enfermagem frente à obesidade infantil como forma de prevenção e orientação, visto que o profissional da saúde está diariamente em contato com esta realidade.

Palavras-chave: Obesidade infantil, Fatores de risco, prevenção, enfermeiro.

\section{INTRODUÇÃO}

A relevância científica desse estudo incide em buscar na literatura o conhecimento de novas tecnologias e experiências acerca da temática, permitindo informações atualizadas embasadas a respeito da importância da orientação preventiva do enfermeiro diante de um prognóstico ou diagnóstico confirmado em que crianças acima do peso possam desenvolver a obesidade infantil.

A obesidade como uma condição clínica é comparada ao um estoque excessivo de gordura no organismo, o que provoca males à saúde com peculiaridades de diferentes fatores, onde incorrem fatores ambientais, psicossociais, genéticos, hormonais e metabólicos. (Gomes, 2012).

Consoante dados da associação brasileira para o Estudo da Obesidade e da Síndrome Metabólica-ABESO, no Brasil a obesidade cresce progressivamente, um número reduzido de dados indicam que $10 \%$ ou mais da população brasileira está acima do peso, ou seja, se enquadra em sobrepeso e obesidade, sendo as crianças com $11 \%$ desse percentual. (ABESO,2017).

A Organização Mundial de Saúde aponta a obesidade como um dos maiores problemas de saúde pública no mundo. A projeção é que, em 2025, cerca de 2,3 bilhões de adultos estejam com sobrepeso; e mais de 700 milhões, obesos. O número de crianças com sobrepeso e obesidade no mundo poderia chegar a 75 milhões, caso nada seja feito. (ABESO/2017).

A obesidade infantil é um distúrbio que aumenta progressivamente no Brasil, coloca em foco doenças crônico-degenerativa a exemplo da Hipertensão Arterial e o 
Diabetes Mellitus, além do desenvolvimento de diversos transtornos psicossociais como a ansiedade e a depressão. (OLIVEIRA, 2016)

Em comparação a fase adulta, na infância lidar com a educação alimentar torna-se mais complicada, ou seja quando relacionamos as alterações dos costumes e maior interação dos pais com seus filhos, além de uma necessidade de assimilação da criança quanto aos males causados pela obesidade. (MELO, 2004).

O tratamento em crianças com obesidade tem como base a utilização de anotações de alimentos e seus valores de nutrição, estratégias de alteração de costumes para mitigar o acesso ao consumo impróprio de determinados alimentos, capacitação para resolução de dificuldades e análises de reincidência.

As ações preventivas desenvolvidas pelo enfermeiro têm uma considerável importância frente ao entendimento do método a respeito do aumento da obesidade na juventude como um componente importante para o crescimento da atenção e uma maior cautela. A precaução é uma feramente eficaz no combate a obesidade infanto-juvenil, sendo essencial uma melhor assimilação das causas que se relacionam com as atitudes dos pais para encorajar uma maior adesão ao tratamento da obesidade. (GOMES, 2013).

Portanto, tendo um crescente número de crianças com obesidade é importante à orientação preventiva do enfermeiro, fazendo-se necessário que o profissional de enfermagem atue em concordância com o conjunto de ações proposto referentes aos fatores de risco e a prevenção do aparecimento de eventual doença na comunidade infantil, estando capacitado para atuar no papel de ouvir os desejos e consentir o nascimento de uma alteração na vivencia e apresentação de seus problemas e incertezas, gerando caminhos para atingir os resultados almejados.

\subsection{REVISÃO BIBLIOGRÁFICA}

A carga genética associada a fatores e conduta de sedentarismo, alimentação não saudável, são condições que contribuem para o aumento do número de crianças 
com obesidade infantil. Deve-se ter prudência e atenção a evolução de planos de precaução para todas as fases do ser humano. (GOMES, 2013).

O profissional da saúde (enfermeiro) deve ser capaz de defrontar - se com a missão de ouvir os desejos e consentir o aparecimento e a troca de conhecimento, como também a apresentação de suas necessidades e inseguranças, gerando uma direção segura para atingir as metas estabelecidas. (SILVA, 2014).

A obesidade no decurso da fase infantil estar se tornando um grande transtorno para a saúde pública. Este distúrbio aumenta os índices de morbidade e letalidade nesta fase da criança, também reflete a necessidade de um maior cuidado com doenças oportunistas, tais como: pré-diabetes, aumento do colesterol, doenças cardiovasculares, distúrbios nas articulações, entre outras anomalias. (OLIVEIRA, 2016).

Observar a evolução infantil está entre as principais tarefas desempenhadas pela equipe de enfermagem, sendo o enfermeiro o responsável técnico em efetivar, controlar e idealizar práticas que surgiram saúde e qualidade de vida à criança.

Compete a esse profissional da mesma forma gerenciar planos de combate a obesidade infantil ao lidar para mudar essa realidade, seja na comunidade, escolas ou ambiente de trabalho, tendo o compromisso de estar sempre alerta as principais circunstancias que norteiam esse assunto, para compreender de maneira detalhada as questões que circundam este distúrbio infantil. (SOUZA, 2016).

Concerne ao enfermeiro, incluir a comunidade nas atividades e planos tendo em vista a melhoria da qualidade de vida, realizar ações de prevenção de doenças e promoção da saúde, orientações sobre a alimentação saudável prevenindo ganho de peso, proporcionar consultas de enfermagem, monitoração dos dados antropométricos, solicitação de exames complementares para avaliar os casos de riscos e caso seja preciso direcionar para um profissional especializado (SOUSA, 2017). 
Segundo Raquel em seu artigo, descreve que o enfermeiro pode acompanhar as medidas de crescimento e progresso da criança, o valor de referência de cada medida é expresso em gráficos no diário da criança tendo em vista o IMC - índice de massa corporal, para avaliar se a criança está com sobrepeso ou obesidade.

No âmbito escolar o enfermeiro também desenvolve atividades com práticas lúdicas, horários para se alimentar incentivando uma disciplina, orientar sobre a nutrição das crianças, incentivar atividades físicas como brincadeiras, jogos esportivos, cálculos de IMC, avaliar o estado psicossocial da criança e da família, orientar se há aparecimento de doenças oportunistas à obesidade, orientar sobre a necessidade de acompanhamento médico além de fazer palestras educativas. (ROCHA, 2014).

Os enfermeiros podem desenvolver palestras por meio da atenção básica para proporcionar contato com os pais, pois são os pais que determinam quais alimentos estão disponíveis para a criança, tanto a quantidade como a qualidade, assim eles vão adquirindo conhecimento através dessas palestras sobre o peso de seus filhos, estimulando o comprometimento maior na previsão da obesidade infantil no meio familiar.

\subsection{OBJETIVOS}

\subsubsection{OBJETIVO GERAL}

Descrever à importância da orientação preventiva do enfermeiro frente à obesidade infantil através de uma revisão bibliográfica.

\subsubsection{OBJETIVOS ESPECÍFICOS}

Identificar as principais ações de enfermagem na prevenção da obesidade infantil. 


\section{MÉTODOS}

Trata-se de um estudo descritivo-exploratório por meio de um estudo bibliográfico referente à importância da orientação preventiva do enfermeiro diante de um diagnóstico em que crianças acima do peso possam desenvolver a obesidade infantil.

\subsection{SUJEITO}

Crianças com obesidade ou que estejam com sobrepeso.

\subsection{MATERIAL}

A pesquisa foi consolidada mediante artigos selecionados nas bases de dados do Núcleo do conhecimento (Multidisciplinary Scientific Journal), ABESO (Associação Brasileira para o Estudo da Obesidade e da Síndrome Metabólica) e Scielo (Scientifie Eletronic Library Online), usando os descritores, Obesidade infantil; fatores de risco; prevenção e enfermeiro.

\subsection{LOCAL}

Bases de dados em: sites, livros, biblioteca digital, periódicos e revistas cientificas.

\subsection{PROCEDIMENTO}

A pesquisa foi elaborada entre os meses de Fevereiro a Dezembro de 2017, por meio de sites, livros, biblioteca digital e revistas cientificas com temas referentes à importância da orientação preventiva do enfermeiro frente à obesidade infantil, durante este período, foram pesquisados 32 artigos, sendo selecionados apenas 9 artigos, dos quais vieram atingir os critérios de inclusão pré-estabelecidos, sendo incluído os que mais se aproximaram com a proposta abordada que referem as ações do enfermeiro para a orientação de prevenção da obesidade infantil. 


\section{RESULTADOS E DISCUSSÃO}

Esta pesquisa reconheceu a importância da orientação preventiva do enfermeiro frente aos casos de obesidade infantil e, desta forma, identificou-se as principais intervenções da equipe de enfermagem na previsão da obesidade a exemplo de:

Orientações sobre uma alimentação com menos produtos industrializados para cautela quanto ao aumento do peso, oportunizar consultas de enfermagem, fiscalização das informações antropométricas, requerimento de exames complementares para analisar os casos de riscos e caso seja preciso direcionar para um profissional especializado.

O enfermeiro frente aos casos de desencadeamento da obesidade infantil, precisa utilizar técnicas de confrontamento por meio da orientação tanto para os pais, quanto para a criança e desta forma minimizar os problemas de ordem física e psicológicas.

Ouvir os desejos e consentir o aparecimento e a troca de conhecimento, como também a apresentação de suas necessidades e inseguranças, gerando uma direção segura para atingir as metas estabelecidas. (SILVA, 2014).

Muitas crianças não conseguem dialogar com outras pessoas a respeito de seus anseios e suas dificuldades, por isso a necessidade do enfermeiro para permitir que esta criança sinta-se à vontade de expor aquilo que a incomoda em seu corpo e mente e desta forma poder buscar em conjunto com a sua família, formas de enfrentamentos das dificuldades relatadas pela mesma.

Desenvolver palestras por meio da atenção básica para proporcionar contato com os pais, pois são os pais que decidem quais alimentos estão acessíveis para a criança, tanto na porção quanto na qualidade, desse modo eles vão adquirindo conhecimento através dessas palestras sobre o peso de seus filhos, incitando um compromisso maior previsão da obesidade infantil no meio familiar. (OLIVEIRA, 2016). 
Os pais são os fornecedores diretos da alimentação de seus filhos, muitas das vezes estes pais não dão importância do valor calórico que muitos alimentos possuem, é necessário que o enfermeiro possa por meio de diálogos e palestras com estes pais, orientando e determinando estratégias que possam fazer com que diminuam o consumo de alimentos não saudáveis para estas crianças, pais conscientes podem evitar futuros filhos sobrepeso e obesos.

No âmbito escolar, o enfermeiro também desenvolve atividades com recreações, horários para o lanche estimulando uma regra, orientar sobre a nutrição das crianças, incentivar atividades físicas como brincadeiras, jogos esportivos, cálculos de IMC, avaliar o estado psicossocial da criança e da família. (SILVA, 2014).

$\mathrm{Na}$ escola os enfermeiros podem atuar de forma ativa em conjunto com os professores, pois a escola oferece um ambiente mais acessível ao contato com um número maior de crianças, demonstrar por meio de palestras educativas e atividades lúdicas, sendo um importante aliado a esta temática, além de ser uma forma de despertar a atenção da criança, também oferece um entendimento melhor a respeito da prevenção da obesidade infantil.

Acompanhar as medidas de crescimento e desenvolvimento da criança, crescimento e progresso da criança, o valor de referência de cada medida é expresso em gráficos no diário da criança tendo em vista o IMC - índice de massa corporal, para avaliar se a criança está com sobrepeso ou obesidade. (SOUZA, 2017).

O caderno com anotações de saúde da criança, oferece um gráfico onde o enfermeiro pode acompanhar o desenvolvimento da criança em relação a altura e o acréscimo de peso para realizar o cálculo do índice de massa corporal (IMC), parâmetro usado pelo Ministério da Saúde para saber se a criança está tendo um crescimento e desenvolvimento saudável.

Todas estas estratégias e ações desenvolvidas pelos enfermeiros em conjunto com outros profissionais de saúde, pais ou responsáveis pela criança e sociedade em geral, são capazes de precaver e monitorar o progresso ou o controle de sobrepeso 
e obesidade infantil em crianças, é imprescindível que não só o enfermeiro, mas quaisquer pessoas que estejam comprometidas nesta questão, visto que é considerada um grande transtorno de saúde pública no planeta, tornando-se um dos principais desencadeadores de enfermidades crônicas e degenerativas, tais como: pressão alta (hipertensão arterial), diabetes mellitus e doenças cardiovasculares em crianças.

\section{CONCLUSÃO}

Portanto, através dos métodos utilizados nesta pesquisa bibliográfica sobre a importância da orientação preventiva do enfermeiro frente a obesidade infantil, foram encontradas diferentes formas de atuação de orientação preventiva do enfermeiro na busca pelo melhor método de enfrentamento que vai desde uma simples orientação sobre hábitos alimentares saudáveis, a orientações mais específicas, para exemplo das estratégias de enfrentamento de excesso de peso em crianças ao empreender e adaptar essa realidade, tanto no ambiente escolar, quanto no meio social, precisando estar alerta aos aspectos que transpassam esse tema, para procurar compreender de forma profunda os assuntos relacionados nesta problemática, sejam de ordem social, físicas ou psicológicas.

\section{REFERÊNCIAS}

ABESO. Página institucional. Mapa da obesidade. Disponível em:< https://abeso.org.br/obesidade-e-sindrome-metabolica/mapa-da-obesidade/>. Acesso em: 14 de maio de 2017.

DÁQUER, Adriana Fernandes C. Psicoterapia é aliada no tratamento da obesidade:Disponívelem:<htt:/www.obsidadeinfantilnao.com.br/poblicacoes/artigos/ psicoterapia e aliando tratamento da obesidade>. Acesso: 21 de maio de 2017.

EDMILSON, Sousa. et.al. O papel do enfermeiro na obesidade infantil. Disponível em:<http://revista.faciplac.edu.br/. Acesso em: 31 de maio de 2017. 
GOMES, Ana Lidia Garcia. Obesidade infantil: Uns quilos a mais hoje, uns anos a menos

no

futuro.

Disponível:>https://paginas.uepa.br/ccbs/edfisica/files/2013.Acesso em:31 de maio de 2017.

GOMES, Roberta de Figueiredo et al. Aspectos psicológicos da obesidade infantil. Efdeportes.com, ano17, n.173, out. 012, Disponível em: <http://www.efdeportes.com/efd173/aspectos psicológicos da obesidade infantil>. Acesso em: 11 maio 2017.

MELO, Elza D. de, Vivian C. Luft, Flavia Meyer. Obesidade infantil: como podemos ser eficazes? Disponível em:<http://www.scielo>. Acesso em: 21 de maio 2017.

OLIVEIRA, Costa. et. al. Educação física escolar e a obesidade infantil. Revista Científica Multidisciplinar Núcleo Do Conhecimento, Ano 1. Vol. 10, p. 87-101. Disponível<https://www.nucleodoconhecimento.com.br/educacao/obesidadeinfantil>.Acesso em: 19 de maio de 2017.

PINTO, Fernando Teixeira. Auditoria contínua: um novo paradigma de auditoria. Disponível em:< http://recipp.ipp.pt/bitstream. FernandoPinto_2011.pdf>. Acesso em: 21 de maio de 2017.

ROCHA, Raquel Edna Silva. Et.al. O papel do enfermeiro na prevenção da obesidade infantil. Disponível em:<htt://www.efdeportes.com./>. Acesso em: 31 de maio de 2017.

SANTANA, M. L; Carmagnani, M. I. Programa Saúde da Família no Brasil: um enfoque sobre seus pressuposto básicos, operacionalização e vantagens. Saúde e Sociedade. Disponível em: <http://www.efdeportes.com/efd199/enfermeiro-naprevencao-da-obesidade-infantil.htm>. Acesso 13 de maio 2017.

Enviado: Janeiro, 2021. 
Aprovado: Março, 2021.

RC: 78253

Disponível em: https://www.nucleodoconhecimento.com.br/saude/orientacaopreventiva 